\title{
Review of life expectancies at birth for Saudi Arabia, 2010-16: A research note
}

\author{
Sulaiman $\mathrm{Bah}^{1}$
}

\section{Introduction}

Saudi Arabia is centrally located in the Middle East. It is the largest Middle Eastern country, with the largest economy. In 2015, its population size was 31.4 million, the fifth-largest in the Middle East but the largest in the Arabian Gulf. While the economy was previously strongly oil-based, decreases in oil prices have resulted in a change in Saudi Arabia's strategy, to reduce dependency on oil. For this reason, Saudi Arabia launched a very bold vision in April 2016, called "Vision 2030," in which health and other economic and development goals were outlined together with strategies on how to achieve them (KSA 2016). Evaluating the achievements of the health goals for the Saudi Arabian vision for 2030 requires a strong empirical basis. Otherwise, gains would not be accurately measured nor easily detected, leading to frustrations that program goals are not being met. This calls for the choice of an appropriate KPI to be used for monitoring the gains made. One of the important summary indicators of health status is life expectancy at birth. This indicator is widely used for goal-setting and is included in the United Nations Millennium Development Goals and in the calculation of the Human Development Index. The life expectancy at birth indicator is also mentioned in the "Vision 2030," and expected targets have been defined. Before measuring gains in life expectancy, we first need to agree on a reference point. The question posed in this paper is "How accurate are the baseline values of life expectancy at birth in Saudi Arabia?" The second question, which follows by implication, is "How accurate are the life tables from which life expectancies at birth are derived?"

Relatively accurate national life tables are obtained under three conditions: (1) when registration of deaths is complete; (2) when the year under consideration is a census year; and (3) when the age reporting is good. Inaccuracies are introduced into the life tables as one departs from any one or more of these crucial pivots. For non-census years (intercensal or postcensal) there is a need for accurate estimation of the population by age and sex for accurate life tables to be constructed. Methods for obtaining population estimates for non-census years are summarized in Appendix 1. When the registration of deaths is complete, which reflects the relative functioning of the civil registration/vital statistics (CR/VS) system, the production of a period life table is fairly straightforward. It only needs deaths data broken down by age and gender, and additional information on population, also by age and gender. These are used to calculate age-specific death rates separately for males and females. The life table model assumes that these computed age-specific death rates remain fixed, and they are used to compute hypothetical life table values (e.g., life expectancy at birth) through a set of well-established formulae. As such, the life table measure, life expectancy at birth, is years expected to be lived if the population under study experienced these observed age-specific death rates. When there is a functional CR/VS system and death registration is relatively high but incomplete or over-complete, the percentage incompleteness or overcompleteness can be estimated and used to adjust the registered deaths data, which are subsequently used to obtain the life tables. This is where the "objective science" in life table construction ends. When the completeness of death registration is low or is unknown, life tables are constructed using other sources of data-for example, census or survey data — through the use of indirect techniques of demographic estimation and modelling. This is an area of "subjective science" in which there is some latitude for disagreement.

1. College of Public Health, Imam Abdulrahman Bin Faisal University (formerly University of Dammam), P.O. Box 2435, Dammam 31441, Saudi Arabia; email:sbah@iau.edu.sa. 
Country life tables are produced by both national organisations (e.g., national statistics offices) and international organizations. When the death registration is complete, there is, in most cases, agreement between the life tables produced by national organizations and those produced by international organizations. When death registration is incomplete, the different methods used by different organizations might lead to different results because of the larger degree of uncertainty involved and the subjectivity in some of the technical decisions being made. A noteworthy point to mention is that not all international organizations calculate life tables, and a large number of them just report the estimates published by other sources. Some of the leading international bodies that produce life tables for different countries are the WHO, the United Nations Population Division (UNPD), the World Bank, and the Human Life-Table Database (HLD) group.

The aim of this study is to review the literature on published life expectancies at birth for Saudi Arabia in the 2010s. The plausibility of the figures is discussed, using internal consistency checks and external demographic logical consistency checks. Recommendations are then made on possible options for the way forward.

\section{Methods}

The study consists of a desktop review of documents. Two sources of data were used for published life tables: national and international reports. The national reports were from the Ministry of Health and from the General Authority for Statistics. For international reports and grey literature, Google and Bing searches were done on published life expectancies for Saudi Arabia. The main search term used was "Saudi Arabia life expectancy at birth." This was supplemented by researching the websites of the some of the aforementioned leading international organizations involved in producing life tables. The results were filtered for relevance and for data that showed life expectancies at birth from 2010 onwards. The results were collated and compiled into tables. The results show the website sources and dates when the data were accessed.

\section{Results}

The results obtained are shown in two tables. Table 1 shows the life expectancies at birth from the yearbooks of the Ministry of Health and from a press release of the Ministry of Health. Table 2 shows the life expectancies at birth from international sources. Table 1 shows several observations. First, that the life expectancies at birth for both males are females are in the early to mid-seventies. Second, that the life expectancy at birth of females is higher than that of males for any given year, with the difference being less than four years. The last observation is that the life expectancy at birth for both males and females combined showed a local peak in 2013. This gives the impression that the life expectancies at birth were constant between 2010 and 2012 and between 2014 and 2016. In between these two periods there was a sudden increase in 2013, followed by a sudden fall the year after.

Table 1. Life expectancies for Saudi Arabia as published in by the Saudi Ministry of Health/Central Statistics Office, 2010-16

\begin{tabular}{lrrrrrrc}
\hline & $2010^{1}$ & $2011^{1}$ & $2012^{1}$ & $2013^{1}$ & $2014^{1}$ & $2015^{1}$ & $2016^{2}$ \\
\cline { 2 - 8 } Males & 72.6 & 72.7 & 72.8 & 72.9 & 73.1 & 73.1 & - \\
Females & 74.9 & 75.1 & 75.2 & 75.4 & 75.6 & 75.7 & - \\
F-M Difference & 2.3 & 2.4 & 2.4 & 2.5 & 2.5 & 2.6 & \\
\hline Overall & 73.7 & 73.8 & 73.8 & 75.0 & 74.2 & 74.3 & 74.3 \\
\hline Sources: \\
1. Ministry of Health. http://www.moh.gov.sa/en/ministry/statistics/book/pages/default.aspx \\
$\quad$ (accessed 16 April 2017) \\
2. Ministry of Health. http://www.moh.gov.sa/en/Ministry/MediaCenter/News/Pages/ \\
$\quad$ News-2016-11-03-002.aspx (accessed 5 April 2017)
\end{tabular}


Bah: A review of life expectancies at birth for Saudi Arabia, 2010-16

Table 2. Life expectancies for Saudi Arabia as published by international sources, 2010-16

\begin{tabular}{|c|c|c|c|c|c|c|c|c|c|c|c|c|c|c|c|c|c|c|}
\hline \multirow[b]{2}{*}{ Males } & \multicolumn{2}{|c|}{$2010^{1,2}$} & \multicolumn{2}{|c|}{$2011^{2,1}$} & \multicolumn{5}{|c|}{$2012^{2,1,3,4,5}$} & \multicolumn{4}{|c|}{$2013^{6,7,8,9}$} & \multicolumn{2}{|c|}{$2014^{10,11}$} & \multicolumn{2}{|c|}{$2015^{12,13}$} & \multirow{2}{*}{$\frac{2016^{14}}{73.2}$} \\
\hline & - & 72.6 & 72.7 & - & 72.8 & - & - & - & - & - & 74.0 & 74.0 & - & - & - & 73.0 & 77.4 & \\
\hline Females & - & 74.9 & 75.1 & - & 75.2 & - & - & - & - & - & 77.0 & 78.0 & - & - & - & 76.0 & 82.2 & 77.4 \\
\hline F-M Differ & ence & 2.3 & 2.4 & & 2.4 & & & & & & 3.0 & 4.0 & & & & 3.0 & 4.8 & 4.2 \\
\hline Overall & 74.3 & 73.7 & 73.8 & 74.2 & 73.9 & 74.0 & 74.1 & 76.0 & 75.3 & 74.2 & 75.0 & 76.0 & 75.5 & 74.3 & 74.0 & - & - & 75.3 \\
\hline
\end{tabular}

Sources:

1. United Nations Statistics Division: http://data.un.org/Data.aspx?q=life+expectancy+at+birth\&d=PopDiv\&f=variableID $\% 3 a 68$ (accessed 16 April 2017)

2. United Nations Economic and Social Commission for Western Asia: https://www.unescwa.org/publications/bulletin-population-andvital-statistics-escwa-region-issue-no-16 (accessed 19 April 2017)

3. Islamic Development Bank. Key Socio-Economic Statistics on IDB Member Countries. Statistical Mongraph No. 34 . Table 1.9. http://www.isdb.org/irj/go/km/docs/documents/IDBDevelopments/Internet/English/IDB/CM/Publications/Statistical_Monograph/ Monograph2014.pdf (accessed 5 April 2017)

4. WHO. Saudi Arabia: WHO statistical profile. http://www.who.int/gho/countries/sau.pdf (accessed 5 April 2017)

5. Unicef. https://www.unicef.org/infobycountry/saudiarabia_statistics.html (accessed 4 April 2017)

6. United Nations Statistics Division: http://data.un.org/Data.aspx?q=life+expectancy+at+birth\&d=PopDiv\&f=variableID\%3a68 (accessed 16 April 2017)

7. Arab News. http://www.arabnews.com/news/496706 (accessed 4 April 2017).

8. WHO. World Health Statistics, 2015. http://www.who.int/gho/publications/world_health_statistics/EN_WHS2015_Part2.pdf?ua=1 (accessed 5 April 2017)

9. Islamic Development Bank. Key Socio-Economic Statistics on IDB Member Countries. Statistical Mongraph No. 35. Table 1.9. http://www.isdb.org/irj/go/km/docs/documents/IDBDevelopments/Internet/English/IDB/CM/Publications/Statistical\%20 Monograph\%20No.\%2035\%20Final.pdf (accessed 4 April 2017)

10. United Nations Statistics Division: http://data.un.org/Data.aspx?q=life+expectancy+at+birth\&d=PopDiv\&f=variableID $\% 3 a 68$ (accessed 16 April 2017)

11. The World Bank. WDI tables, Table 2.21. http://wdi.worldbank.org/table/2.21 (accessed 5 April 2017)

12. WHO. http://apps.who.int/countries/sau/en/ (accessed 9 April 2017)

13. Institute for Health Metrics and Evaluation. http://www.healthdata.org/saudi-arabia (accessed 4 April 2017)

14. Geoba.se. http://www.geoba.se/index.php (accessed 30 Nov 2017)

As can be seen from Table 2, some international sources report only the total life expectancies at birth (for both males and females), while others report them along with the male/female breakdown or only the latter. As with the national estimates, one observation is that for any specific year, the life expectancy at birth is higher for females than males. Another observation is that the life expectancies in Saudi Arabia in the 2010s are in the mid- to late seventies (with one exception). For both males and females combined, the life expectancy at birth was hovering around the mid-seventies during the study period.

Table 2 shows several differences. The table shows that within any given year there are differences in estimates of life expectancy at birth from the different sources. The largest difference is for 2015. In that year, the difference in the estimates of life expectancy at birth for females from two different agencies is 6.2 years. The lowest difference in the estimates from different agencies is for 2011, followed by 2013. For 2011 the difference is minimal, 0.2 year, while for that of 2013 the difference is 1.8 years. Even within the same source, there are some difficulties in reconciling the results for different years. For example, according to the WHO estimates, life expectancy at birth for both males and females combined stayed fixed from 2012 to 2013 and (implicitly) declined by 2015. For females, the WHO estimate of life expectancy at birth declined from 78 years in 2013 to 76 years in 2015. 


\section{Discussion}

The first consensus emerging from the results is that the life expectancy at birth for Saudi Arabia in the 2010 s is in the 70s. This is demographically plausible, given the large decline in infant and child mortality experienced in Saudi Arabia decades ago - and given the change in epidemiological profile from one in which infectious diseases were dominant to one in which chronic diseases are now dominant (Ministry of Health 2014). In fact, the change in epidemiological profile itself implies that the life expectancy at birth had entered the 70s. The second consensus emerging from the results is that the life expectancies at birth for females are higher than those for males. This again is demographically plausible, as there is a vast amount of literature supporting a male disadvantage in life expectancy at birth. This disadvantage has social, environmental, behavioural, and biological determinants (Richard et al. 2010; Trovato and Lalu 1996; Waldron 1995). This is further strengthened by the high rates of accidents among Saudi males and by the higher prevalence of smoking among Saudi males (Mansuri et al. 2015; Ministry of Health 2014).

For the Saudi Arabian published figures, the constancy in the estimates of life expectancy at birth and the local peak in 2013 are demographically questionable given the stability in Saudi Arabia in the 2010s. Further, the net change in life expectancy from 2010 to 2016 is less than one year. This also seems questionable, considering the general improvements in health and living conditions in Saudi Arabia in the 2010s.

For the life tables published by international organizations, differences in life expectancies at birth of within one year are acceptable, given the slight differences in methods used. However, differences in life expectancies at birth of over six years (as in the females for 2015) are unacceptable.

To understand the reasons for the different estimates of life expectancies as reported by international organizations, one needs to unpack the process of production and subsequent publication of life tables. Details of the methods used by international organizations are given in Appendix 2.

There are three main reasons for the observed discrepancies in life tables. The first one relates to a delay in the submission of reported deaths data to the WHO/UNPD. When these organizations do not receive up-todate data, they use any latest available data and make the best of them. The latest deaths data available to WHO/ UNPD for Saudi Arabia were for 2009. This was one of the inputs used in producing Saudi Arabian life tables for 2009 onwards. The second reason relates to lack of information on the percentage completeness of death registration in Saudi Arabia. In a survey carried out by the International Institute for Vital Registration and Statistics (IIVRS) in the 1980s, the completeness of registration of births and deaths for Saudi Arabia was reported as "unknown" (IIVRS 1988). About twenty years later, in a 2007 report on CR/VS for Western Asia, it was reported for Saudi Arabia that "There is no assessment for the coverage of the civil registration system in the country" (ESCWA 2007). Lastly, in the 2014 WHO report on country-level causes of death, the completeness of death registration for Saudi Arabia was unstated. The third reason is that international organizations keep on changing (refining) their methods and updating their databases. As such, newer estimates could be incompatible with older estimates. According to the WHO estimates, for example, the total life expectancy at birth for Saudi Arabia stayed the same from 2012 to 2013 (76 years) and declined by 2015 (unstated but less than 76). On the other hand, the United Nations Economic and Social Commission for Western Asia is not one of those organizations that calculates life tables; it merely reported the figures published by the Saudi Arabia. For this reason, its results cannot be discussed further here.

With regard to using life expectancy at birth as a KPI for monitoring the achievement of health goals for the 2030 vision, the choice is a good one. However there are a few distinct tasks to be carried out for accurate monitoring of the indicator. The first is to estimate the completeness of death registration in Saudi Arabia. This should be done both regionally and nationally. The second task is to develop a national life table program at the General Authority for Statistics, building on its ongoing efforts. The third is to be current in the submission of population and deaths data to the WHO/UNDP. Hopefully, with these in place, the uncertainties in the life tables estimates (within source and between sources) can be narrowed down, if not eliminated. The monitoring of life expectancies at birth would then be placed on a solid footing. 


\section{Conclusion}

There is no convincing evidence about the true level of life expectancy at birth for Saudi Arabia in the 2010s or earlier. The only consensus reached by the literature is that life expectancy at birth is in the 70s and that female life expectancy at birth is higher than that of males. It is crucial that registered deaths be published in a timely manner and that estimation of the completeness of death registration in Saudi Arabia be carried out. These will help in constructing accurate life tables, which will provide a strong foundation for monitoring the health goals in the Saudi 2030 vision.

\section{References}

ESCWA (United Nations Economic and Social Commission for Western Asia). 2007. Report on the United Nations Workshop on Civil Registration and Vital Statistics for ESCWA Region. Available at: https://unstats.un.org/unsd/ demographic/meetings/wshops/Civil_Registration_Dec07_Cairo/docs/Final\%20report\%20workshop\%20 ESCWA.pdf. [Accessed 17 April 2017]

George, M.V., S. Smith, D. Swanson, and J. Tayman. 2004. Population projections, in The Methods and Materials of Demography. San Diego: Elsevier Academic Press.

IIVRS (International Institute for Vital Registration and Statistics). 1888. Organization and Status of Civil Registration and Vital Statistics in the Arab Countries. Available at: https://www.cdc.gov/nchs/data/isp/033_organization_ and_status_of_civil_regist_and_vital_stat_in_arab_countries.pdf. [Accessed 20 April 2017]

KSA (Kingdom of Saudi Arabia). 2016. Vision 2030: Kingdom of Saudi Arabia. Available at: http://vision2030.gov. sa/sites/default/files/report/Saudi_Vision2030_EN_0.pdf. [Accessed 30 July 2016]

Leddy, Jr., R. 2013. United States Census Bureau. Available at: https://www.census.gov/population/international/ files/pepfar/subntl_pop_est_methods_gsb_uscb_sep13.pdf. [Accessed 6 November 2017]

Mansuri, F.A., A.H. Al-Zalabani, M.M. Zalat, and R. Qabshawi. 2015. Road safety and road traffic accidents in Saudi Arabia: A systematic review of existing evidence. Saudi Medical Journal 36(4):418-24.

Ministry of Health. 2014. Minister of Health Announces the Results of the National Survey for the Health Information in the Kingdom. Available at: http://www.moh.gov.sa/en/ministry/mediacenter/news/pages/news-2014-03-09-001. aspx. [Accessed 6 August 2017]

Rogers, R.G., B.G. Everett , J.M Onge, and P.M. Krueger. 2010. Social, behavioral, and biological factors, and sex differences in mortality. Demography 47(3):555-78.

Swanson, D., and J. Tayman. 2012. Subnational Population Estimates. London: Springer.

Trovato, F., and N. Lalu. 1996. Narrowing sex differentials in life expectancy in the industrialized world: Early 1970s to early 1990s. Social Biology 43(1-2):20-37.

Waldron, I., 1995. Contributions of biological and behavioural factors to changing sex differences in ischaemic heart disease mortality, in Adult Mortality in Developed Countries: From Description to Explanation, edited by A.D. Lopez, G. Caselli, and T. Valkonen. Oxford: Clarendon Press, p. 161-78.

WHO (World Health Organization). 2014. WHO Methods and Data Sources for Country-Level Causes of Death, 20002012. Available at: http://www.who.int/healthinfo/statistics/GlobalCOD_method.pdf. [Accessed 17 April 2017]

2016. WHO Methods and Data Sources for Life Tables, 1990-2015. Available at: http:/ /www.who.int/ healthinfo/statistics/LT_method.pdf. [Accessed 6 August 2017] 


\section{Appendix 1}

\section{Summary of methods for estimating population estimates by age for non-census years}

Estimation of population by age for non-census years are of three types. The first is for the inter-censal period, when data are available for two censuses and estimates are needed for the years in between. The second is for post-census period, when data are needed for the years after the latest census. The last is for the pre-census period, when data are needed for the years earlier than the previous census. For the intercensal period, interpolation methods are used for producing the population estimates by age are. The main interpolation methods are linear, geometric, and exponential interpolation. After these methods have been applied, there is often a need to adjust the totals to match figures (marginal totals) that have been independently obtained. The popular method for this is the method of iterative proportional fitting, also known as the contingency table method. This method (used alone or in combination with other methods) is the method used by the US Census Bureau and is included in their software for population estimation (Population Analysis Software; Leddy 2013). For population estimates for post-census years, many methods are available. The main methods used have been described by several authors (George et al. 2004; Swanson and Tayman 2012). The methods are grouped into three: (1) Trend extrapolation; (2) Cohort-component; and (3) Structural models (George et al. 2004).

All the methods involve the use of assumptions, and hence all the population estimates produced have some amount of uncertainty:

Given the widespread use of population projections for decision making in both the public and private sectors — and the high stakes often associated with those decisions — it is essential that data users have some understanding of the uncertainty inherent in population projections (George et al. 2004).

The uncertainty in the population estimates (for non-census years) is reflected in uncertainty in the estimates of indices that have population inputs in their calculations, including those of life expectancies at birth.

\section{Appendix 2}

\section{Technical details of life table production by leading international organizations}

The leading international organizations involved in the international production of life tables are the WHO, the United Nations Population Division (UNPD), and the Human Mortality Database (HDM) Group. The three organizations have strengths in different areas and hence complement each other. When countries collect population and registered deaths data and compute life tables, they submit these life tables and their inputs (deaths and population data adequately broken down) to the WHO and UNPD, either as part of their reporting obligations to the United Nations or in response to questionnaires sent out by them. Of these life tables submitted, those with the highest quality are included in the Human Mortality Database (complete registration of deaths with adjustment for misreporting in the oldest ages). These life tables serve as a reference mortality dataset for both the UNPD and the WHO.

Of interest to us are the life table related reports from WHO and the UNPD. The two latest reports of the UNPD are the 2012 revision of the World Population Prospects report (WPP 2012) and the 2015 revision of the same report (WPP 2015). Similarly, the two latest reports of the WHO are the causes of death report for 2000 to 2012 (WHO 2014) and the report on life tables from 1990 to 2015 (WHO 2016). In WPP 2015, the UNPD accepted the HDM life tables values for twenty-one countries and published them. For other countries with useable registered deaths data, the UNPD made adjustments for completeness of death registration be- 
fore computing the life tables. For other countries with weak vital statistics systems, data from multiple sources and an array of methods were used to produce life tables for five-year periods (quinquennial life tables). For all countries, the UNPD computed estimates of the population and produced life tables for the period 1950 to 2015. The life expectancies at birth obtained from these life tables were then used in a probabilistic model and projected to obtain estimates from the period 2015 to 2100.

In the WHO 2014 report, the WHO used the population estimates from the different countries, some of the life tables from WPP 2012, and different sets of methods for different countries, based on the quality of data received. In the WHO 2016 report, the WHO used the population estimates from WPP 2015 (not the country's reported population figures), some of the life tables from WPP 2015, and different sets of methods for different countries, based on the quality of data received.

In the WHO 2014 report, Saudi Arabia was placed under the "Group D" countries. For those countries, the data used to comprise the life tables were obtained from WPP 2012 and child mortality estimates from United Nations Interagency Group on Child Mortality Estimation (UN IGME). For Saudi Arabia in particular, the deaths registration data used are from 2000-06 and 2009.

In the WHO 2016 report, Saudi Arabia was grouped under "WPP" countries. For those countries, the life tables were constructed from interpolated mortality rates from WPP 2015 quinquennial life tables in general. For Saudi Arabia in particular, the methods used: (1) official estimates of life expectancy at birth for 2010-13; and (2) for 1995-2010, life tables based on the Demographic surveys of 2004 and 2007 and the 2004 census. Registered deaths for 2009 were also taken into account.

In summary, as the Saudi Arabian data available to the WHO/UNPD is scanty, the WPP 2016 life tables obtained for Saudi Arabia are heavily model-based, and the WHO 2016 report further models on those heavily modelled figures. In WHO 2016, the WHO exercises caution by making the following remark:

These WHO estimates of mortality and life expectancies should not be regarded as the nationally endorsed statistics of Member States, which may have been derived using alternative methodologies and assumptions (WHO 2016). 